\title{
Evaluation of Tumor-Induced Osteomalacia with 111In-Pentetreotide Scintigraphy
}

\author{
Fathima Fijula Palot Manzil, Pradeep G. Bhambhvani, and Janis P. O’Malley \\ Division of Nuclear Medicine, Department of Radiology, University of Alabama at Birmingham, Birmingham, Alabama
}

\begin{abstract}
In cases of nonhereditary osteomalacia associated with hypophosphatemia and inadequate response to vitamin D supplementation, one should consider the possibility of tumor-induced osteomalacia, a paraneoplastic syndrome caused by small mesenchymal tumors often found in obscure locations. We present a case of tumor-induced osteomalacia in which ${ }^{111}$ In-pentetreotide scintigraphy aided in accurate localization of the culprit brachial plexus tumor and cure after resection.
\end{abstract}

Key Words: tumor-induced osteomalacia; ${ }^{111}$ In-pentetreotide scintigraphy; somatostatin receptors

J Nucl Med Technol 2013; 41:299-301

DOI: 10.2967/jnmt.113.126763

$\mathbf{T}$ umor-induced osteomalacia or oncogenic osteomalacia is an uncommon disorder presenting with bone pain and fractures. It is characterized by renal phosphate wasting, hypophosphatemia, and osteomalacia and is usually caused by benign mesenchymal tumors (1). We present a case of tumor-induced osteomalacia in which ${ }^{111}$ In-pentetreotide scintigraphy (OctreoScan; Mallinckrodt) aided in accurate localization of the culprit brachial plexus tumor and cure after resection. ${ }^{111}$ In-pentetreotide imaging is useful for evaluating not only neuroendocrine tumors but also other tumors expressing somatostatin receptors, such as those causing tumor-induced osteomalacia, which are often small and found in obscure locations.

\section{CASE REPORT}

A 43-y-old man presented with bone pain and nontraumatic fractures of the right calcaneus and lumbar spine. Radiographs and dual-energy x-ray absorptiometry revealed osteopenia. The laboratory work-up showed a normal level of serum calcium $(9.2 \mathrm{mg} / \mathrm{dL}$; reference range, 8.4-10.2 $\mathrm{mg} / \mathrm{dL}$ ), an increased level of alkaline phosphatase (244

\footnotetext{
Received May 30, 2013; revision accepted Jul. 16, 2013.

For correspondence or reprints contact: Fathima Fijula Palot Manzil, Division of Nuclear Medicine, 619 19th St. S., University of Alabama at Birmingham, Birmingham, AL 35249.

E-mail: drfijulasurjith@yahoo.com

Published online Oct. 24, 2013.

COPYRIGHT @ 2013 by the Society of Nuclear Medicine and Molecular Imaging, Inc.
}

units/L; reference range, 39-117 units/L), undetectable 1,25dihydroxyvitamin $\mathrm{D}(<8 \mathrm{pg} / \mathrm{mL}$; reference range, $18-92$ $\mathrm{pg} / \mathrm{mL})$, and a decreased level of serum phosphorus $(1.3$ $\mathrm{mg} / \mathrm{dL}$; reference range, $2.4-5 \mathrm{mg} / \mathrm{dL}$ ). Fibroblast growth factor 23 , key to pathogenesis of tumor-induced osteomalacia, was also elevated (320 relative units $/ \mathrm{mL}$; reference range, $\leq 180$ relative units $/ \mathrm{mL}$ ). A planar 4 -h whole-body ${ }^{99 \mathrm{~m}} \mathrm{Tc}-$ methylene diphosphonate $(22 \mathrm{mCi})$ bone scan suggested osteomalacia (Fig. 1). Because tumors causing tumor-induced osteomalacia may express somatostatin receptors, ${ }^{111} \mathrm{In}$ pentetreotide (223.5 MBq [6.04 mCi]) scintigraphy was done $24 \mathrm{~h}$ after radiotracer administration. Planar and SPECT images (Fig. 2) revealed focal uptake in the right axilla, which correlated with a well-circumscribed lesion within the coracobrachialis muscle on CT (Fig. 3) and MR imaging (Fig. 4). During surgery, the tumor was confirmed to arise from the musculocutaneous nerve of the right brachial plexus and was successfully resected. Pathologic findings were consistent with a benign spindle cell tumor. After resection, the patient reported improvement in symptoms, and biomarkers were also improved (serum phosphorus, $4.7 \mathrm{mg} / \mathrm{dL}$; fibroblast growth factor 23,92 relative units $/ \mathrm{mL})$.

\section{DISCUSSION}

Osteomalacia is a bone disorder characterized by decreased mineralization of newly formed osteoid at bone turnover sites. Disorders causing osteomalacia include those associated with abnormal vitamin D metabolism, osteoid mineralization defects, and hypophosphatemia. Disorders associated with hypophosphatemia include hereditary (X-linked, autosomal-dominant, and autosomalrecessive) and acquired (tumor-induced osteomalacia) forms, which are clinically indistinguishable. Characteristic findings include renal phosphate wasting and inadequate response to vitamin D replacement. In adults, absence of a family history along with elevated levels of fibroblast growth factor 23 should raise suspicion of tumor-induced osteomalacia. The pathogenesis of tumorinduced osteomalacia is based on tumor expression of fibroblast growth factor 23 , which inhibits proximal renal tubular reabsorption of phosphate and downregulates renal conversion of 25-hydroxyvitamin $\mathrm{D}$ to its active form, 1,25-dihydroxyvitamin $\mathrm{D}$, resulting in phosphate wasting and low vitamin D levels. Finding the culprit 


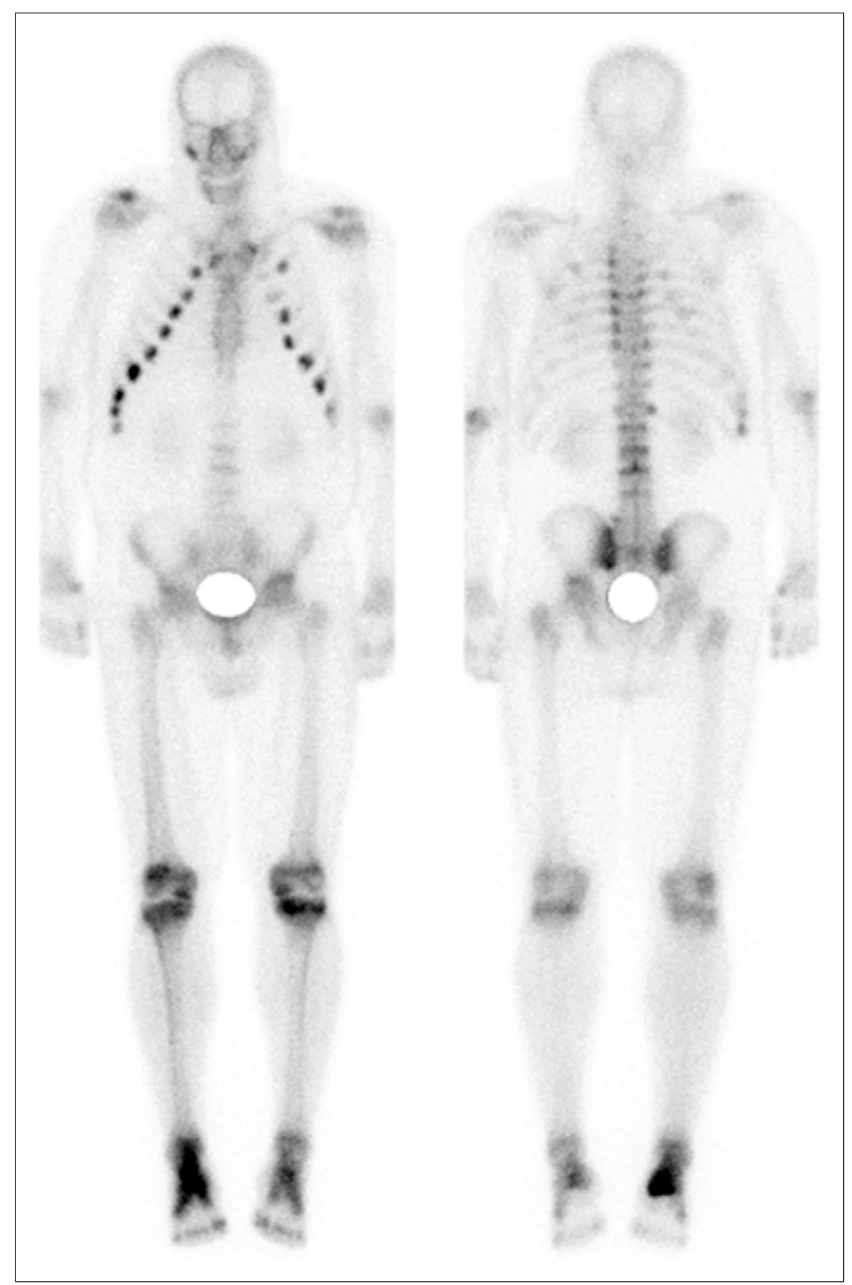

FIGURE 1. 99mTc-methylene diphosphonate bone scan reveals rosary-bead pattern of uptake at costochondral junctions suggestive of osteomalacia or other metabolic bone disease. Uptake related to right calcaneal fracture and subacute compression fractures of upper lumbar vertebrae are also evident.

tumor is a major diagnostic challenge because the tumors are usually small and in obscure locations, such as bone or soft tissue. ${ }^{111}$ In-pentetreotide scintigraphy is useful because the tumors frequently express somatostatin receptors. ${ }^{18} \mathrm{~F}-\mathrm{FDG}$ is another useful radiopharmaceutical that may be applied when ${ }^{111}$ In-pentetreotide scintigraphy has negative findings. Though sensitive, ${ }^{18}$ F-FDG is less specific. Follow-up anatomic imaging (CT, MR imaging) can be done for localization. ${ }^{99 \mathrm{~m}} \mathrm{Tc}-$ HYNIC-TOC (hydrazinonicotinyl-tyr3-octreotide) and ${ }^{68} \mathrm{Ga}$-DOTATOC are other agents that can be used for detection of tumors causing tumor-induced osteomalacia (2-5).

\section{CONCLUSION}

In cases of nonhereditary osteomalacia associated with hypophosphatemia and inadequate response to vitamin D supplementation, one should consider the possibility of

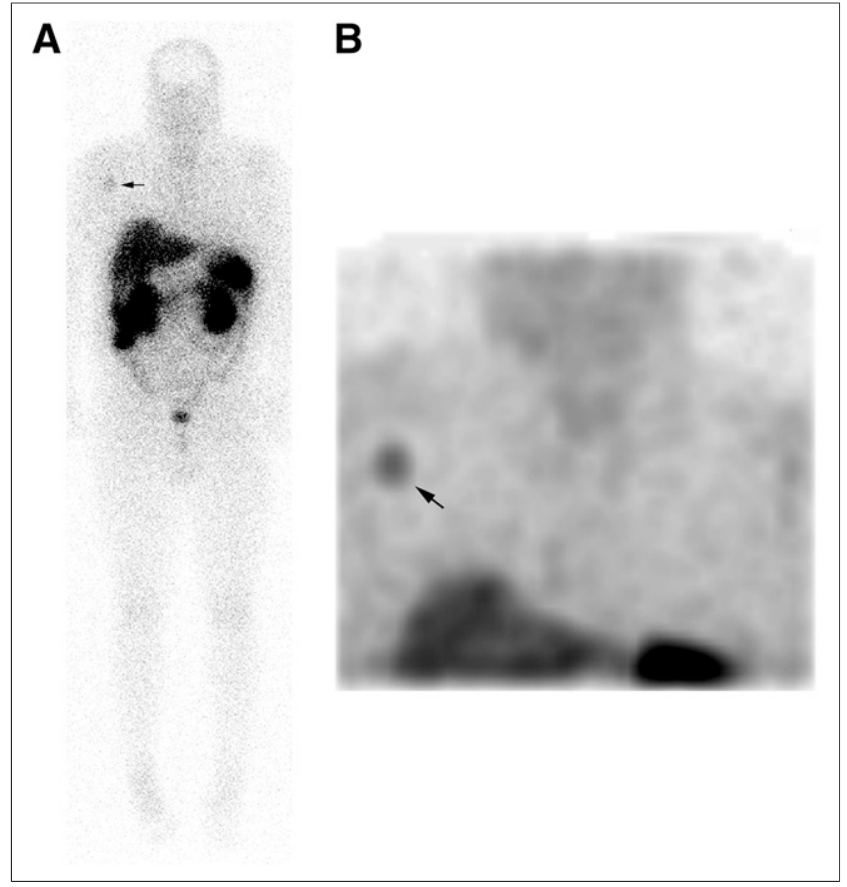

FIGURE 2. ${ }^{111}$ In-pentetreotide planar (A) and SPECT (B) images acquired $24 \mathrm{~h}$ after radiotracer injection depict focal uptake within right axilla.

tumor-induced osteomalacia, a paraneoplastic syndrome caused by small mesenchymal tumors often found in obscure locations. Diagnostic evaluation includes measurement of serum fibroblast growth factor 23 and functional and anatomic imaging, as accurate localization and surgical removal of the tumor are almost always curative. In nonsurgical candidates or when tumors are unidentifiable,

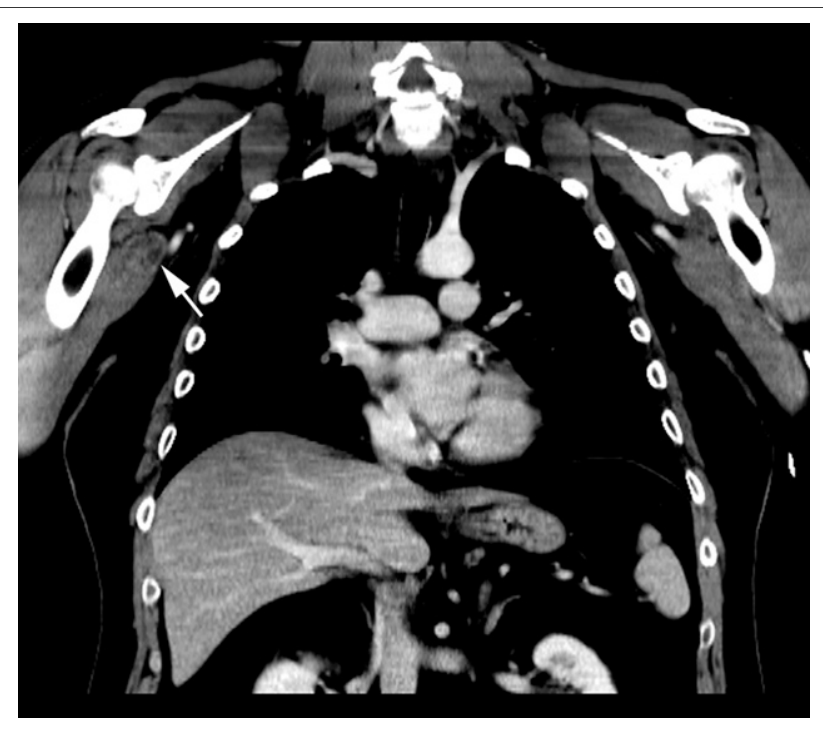

FIGURE 3. Contrast-enhanced coronal CT scan of chest shows well-defined lesion in proximal right coracobrachialis muscle. 


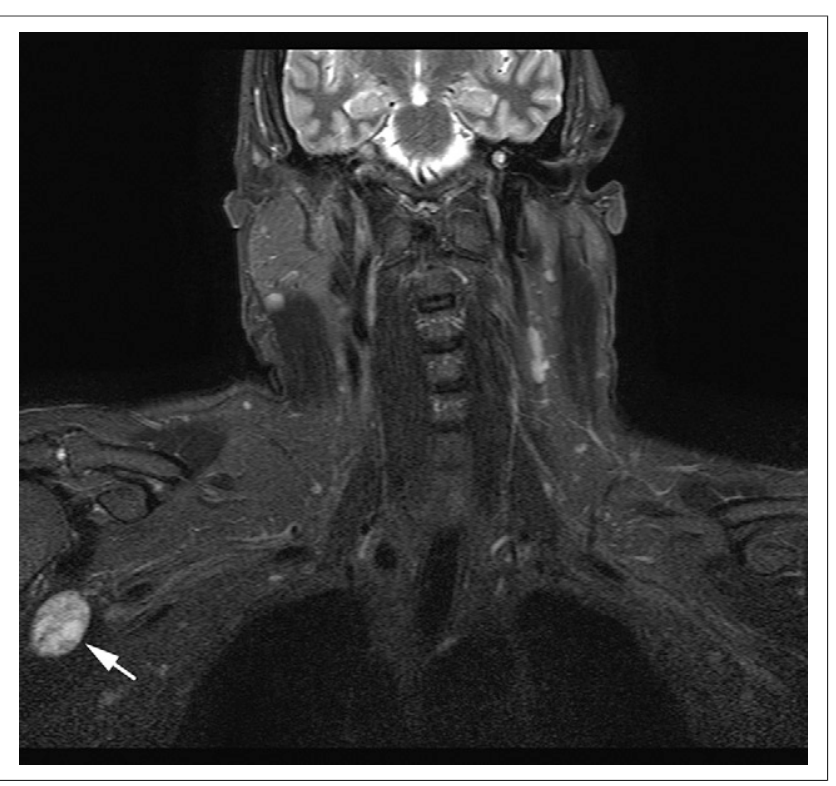

FIGURE 4. Coronal MR image (T2-weighted short- $\tau$ inversion recovery) shows enhancing lesion within right coracobrachialis muscle, surgically confirmed to be arising from right musculocutaneous nerve. phosphorus and vitamin D supplementation and octreotide (e.g., Sandostatin; Novartis) are pharmacologic treatment options.

\section{DISCLOSURE}

No potential conflict of interest relevant to this article was reported.

\section{REFERENCES}

1. Chong WH, Molinolo AA, Chen CC, Collins MT. Tumor-induced osteomalacia. Endocr Relat Cancer. 2011;18:R53-R77.

2. Jing H, Li F, Zhong D, Zhuang H. ${ }^{99 \mathrm{~m}} \mathrm{Tc}-\mathrm{HYNIC-TOC}\left({ }^{99 \mathrm{~m}} \mathrm{Tc}-\right.$ hydrazinonicotinyltyr3-octreotide) scintigraphy identifying two separate causative tumors in a patient with tumor-induced osteomalacia (TIO). Clin Nucl Med. 2013;38: 664-667.

3. Jing $\mathrm{H}$, Li F, Zhuang $\mathrm{H}$, et al. Effective detection of the tumors causing osteomalacia using [Tc-99m]-HYNIC-octreotide ( ${ }^{99 \mathrm{~m} T \mathrm{Tc}-H Y N I C-T O C)}$ whole body scan. Eur J Radiol. 2013;82:2028-2034.

4. Naswa N, Sharma P, Kumar R, Malhotra A, Bal C. Successful localization of residual culprit tumor in a case of tumor-induced osteomalacia using ${ }^{68} \mathrm{Ga}$ DOTANOC PET/CT. Clin Nucl Med. 2013;38:639-640.

5. Hesse E, Moessinger E, Rosenthal H, et al. Oncogenic osteomalacia: exact tumor localization by co-registration of positron emission and computed tomography. J Bone Miner Res. 2007;22:158-162. 